\title{
Agile Manufacturing Resource Excavating and Predicating Based on Time Series Model
}

\author{
Linghong Lai ${ }^{*}$ and Xiaofang Wang \\ Logistics University of People's Armed Police Force, Tianjin, China. \\ alhe2012@126.com
}

\begin{abstract}
Keywords: Agile manufacturing, Resources scheduling, Time series model
Abstract. To meet manufacturing resource selection and scheduling demand in agile manufacturing mode resource management environment, agile manufacturing resource ontology infrastructure was established by means of agile manufacturing resource modulation metadata and ontology. On this basis, agile manufacturing resource excavating and predicating strategy was constructed by the HMM (Hide Markov Model) of time series model. Finally, agile manufacturing resource excavating and predicating model was established to provide a supply for manufacturing resource selection and scheduling in agile manufacturing resource management environment, and to provide an approach for the knowledge extension of agile manufacturing resource excavating and predicating, and for the performance improvement of agile manufacturing mode.
\end{abstract}

\section{Introduction}

Businesses are restructuring and re-engineering themselves in response to the challenges and demands of the 21 st century. The businesses of the 21 st century will have to overcome the challenges of demanding customers who will seek high-quality, low-cost products that are relevant to their specific and rapidly changing needs. The time during which many companies competed based primarily on price tag has gone[1]. Now is the time for companies to compete in the global marketplace, and "push the envelope" in delivery-response, product quality, and overall excellence in customer service and customer satisfaction. Agility addresses new ways of running companies to meet these challenges. Manufacturing has undergone many evolutionary stages and paradigm shifts. The paradigm shifts in going from a craft industry to mass production, then to lean manufacturing, and finally, to agile manufacturing (AM). The concept of agility (flexible and quick responsive manufacturing) will reduce time to reach market with appropriate products/services[2-3].

Agile manufacturing is a term applied to an organization that has created the processes, tools, and training to enable it to respond quickly to customer needs and market changes while still controlling costs and quality. An enabling factor in becoming an agile manufacturer has been the development of manufacturing support technology that allows the marketers, the designers and the production personnel to share a common database of parts and products, to share data on production capacities and problems-particularly where small initial problems may have larger downstream effects. It is a general proposition of manufacturing that the cost of correcting quality issues increases as the problem moves downstream, so that it is cheaper to correct quality problems at the earliest possible point in the process.

However, there are many differences between the new production organization method and traditional enterprise's production management on the production plan, so that there is lack the ability to excavate and predict the manufacturing resources and communicate with other information systems in agile manufacturing.

There are many researches about resources scheduling method of agile manufacturing[4-5].In order to further meet manufacturing resource selection and scheduling demand in agile manufacturing mode resource management environment, agile manufacturing resource ontology infrastructure was established by means of agile manufacturing resource modulation metadata and ontology. On this basis, agile manufacturing mode resource excavating and predicating strategy was constructed by the HMM (Hide Markov Model) of time series model. Finally, agile manufacturing mode resource 
excavating and predicating model was established to provide a supply for manufacturing resource selection and scheduling in agile manufacturing mode resource management environment. The method can provide a new approach to enhance the efficiency of agile manufacturing mode, and extend the knowledge of manufacturing resources optimizing and heighten the automation level of agile manufacturing mode.

\section{Agile Manufacturing Mode Resource Management}

Agile manufacturing resource metadata. Manufacturing resource scheduling is defined as a method for the effective planning of all resources of a manufacturing company. Ideally, it addresses operational planning in units, financial planning, and has a simulation capability to answer "what-if" questions and extension of closed-loop MRP[10-11]. Manufacturing resource belongs to a society resource in concept, but it includes some elements in nature resource. Different agile manufacturing mode resource structures are different, but there is a common characteristic in different agile manufacturing mode resources. By modularization thought, the agile manufacturing resource metadata can be described as Figure 1.

Agile manufacturing resource ontology. As wide use of agile manufacturing resource, new agile manufacturing resource is created. Based on agile manufacturing resource metadata, agile manufacturing resource is divided into information resources, template resources, and knowledge resources by means of ontology definition method. The agile manufacturing resource scope content is shown as Figure 2.
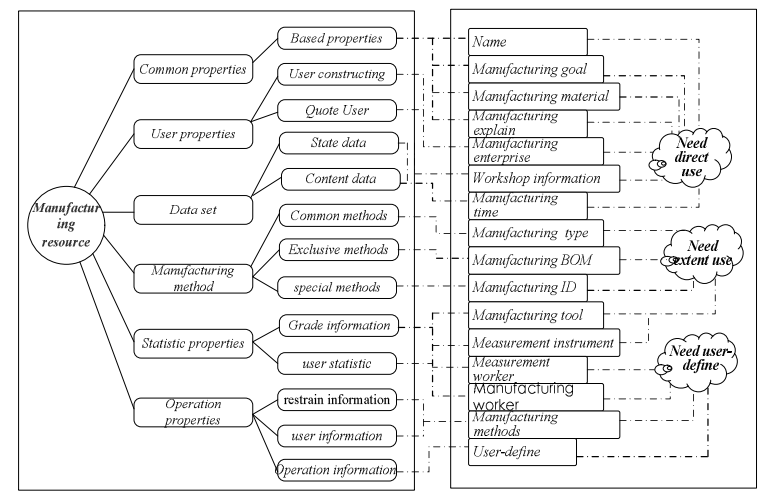

Fig. 1. The agile manufacturing resource metadata

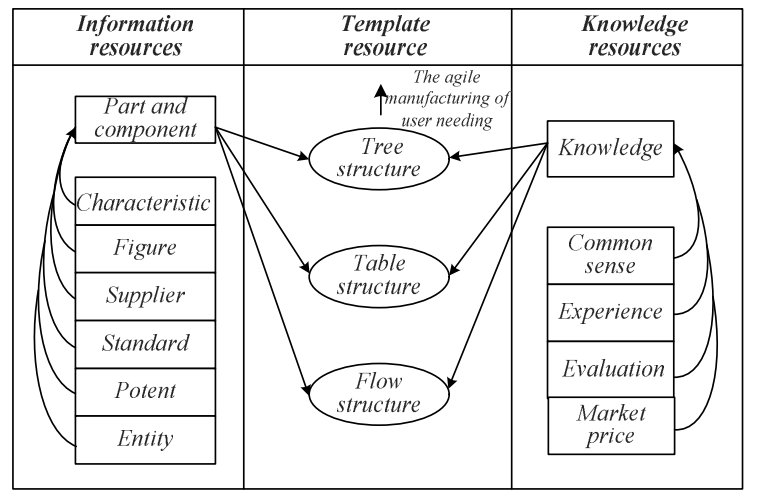

Fig.2. The agile manufacturing resource scope content

Agile manufacturing resource excavating and predicating strategy based HMM. The data excavating and predicating method based on time series model is to find and forecast potential data by means of model parameters, coefficients, residuals, and so on in time series model[7]. A hidden Markov model (HMM) is a statistical Markov model in which the system being modeled is assumed to be a Markov processwith unobserved (hidden) states. An HMM can be presented as the simplest dynamic Bayesian network. The mathematics behind the HMM was developed by L. E. Baum and coworkers[7-8].

A HMM of time series model is an uncertain, random, finitude state automatic machine, and is a combination between non-observation and observation random process. Non-observation random process is Hide Markov line, and is described by parameter A. This line will output Hide Markov order, and is non-observation state. At the same time, observation random process is Hide state order line, and is described by parameter A. This line will output state order, and is observation state.

HMM is described as:

$$
\lambda=\left\{\pi=P\left(q_{1}=s_{i}\right), \quad A=P\left(q_{1+1}=s_{i}\right), \quad B=P\left(o_{l}=v_{k} \mid q_{l}=s_{j}\right)\right\}
$$

Where, $\pi$ is probability vector in initial state, and $\pi=\left\{\pi_{1}, \pi_{2}, \ldots \pi_{3}\right\}$.There is $\pi_{1}=P\left(q_{1}=s_{i}\right), 1 \leq i \leq N . A$ is probability matrix in state transferring, $A=\left\{a_{i j}\right\}_{N \times N}$. There is $a_{i j}=P\left(q_{1+1}=s_{i}\right), 1 \leq i, j \leq N$. $A$ is probability matrix in state transferring, $A=\left\{a_{i j}\right\}_{N \times N}^{N \times N}$. There is 
$a_{i j}=P\left(q_{1+1}=s_{i}\right), 1 \leq i, j \leq N . B$ is probability matrix in observation value, and $B=\left\{b_{j k}\right\}_{N \times N}$. There is $b_{i j k}=P\left(o_{l}=v_{k} \mid q_{l}=s_{j}\right), 1 \leq j \leq N, 1 \leq k \leq M$.

Where, $N$ expresses the state number of Markov line in model, also is the hide state number. The $N$ states are marked as $s_{1}, s_{2}, \ldots s_{N}$. The $t$ time state is defined as $q_{t}$, and $q_{t} \in\left\{s_{1}, s_{2}, \ldots s_{N}\right\}$. $M$ expresses the possible observation number of each state, also is the output state number. The $M$ observation values are marked as $v_{1}, v_{2}, \ldots v_{M}$. The $t$ time state is defined as $o_{t}$, and $o_{t} \in\left\{v_{1}, v_{2}, \ldots v_{M}\right\}$.

Based on HMM characteristic, HMM can reflect autocorrelation of time order in short time. The approximate linear relationship cannot be ensured by the uncertainty of HMM. When now variable and history variable are uncertainty, the uncertainty of agile manufacturing resources can confirmed and reflected by HMM. Agile manufacturing resource excavating and predicating strategy based on HMM is established by AIC (Akaike's Information Criterion) method. AIC (Akaike's Information Criterion) method was proposed by famous Japanese statistician H.Akaik in 1974. This method can solve the applicability and complexity of comprehensive balance modeling problem. AIC can be described as:

$$
\text { AIC }=-2 \log \text { (maximum similar function valve) }+2 \text { (the number of freedom parameter) }
$$

The first symbol of this formula presents the deviation between model state and real distribution state. The deviation is smaller, the model is more complex and model order is higher. The second symbol of this formula will increase when there is more evaluation parameter. At the same time, the deviation is bigger, the model is more simply and model order is littler. The second symbol of this formula will decrease when there is less evaluation parameter. The selection of model order should consider the applicability and complexity of model to acquire minimum the valve of AIC. The mechanism of AIC is described as:

$$
\begin{aligned}
M_{A I C} & =\arg \min _{\mathrm{M}_{\mathrm{i}} \in\{M\}} \operatorname{AIC}\left(M_{i}\right) \\
& =\arg \min _{\mathrm{M}_{\mathrm{i}} \in\{M\}, k \in K}\left[-\log P\left(X \mid M_{i}\right)+k_{i}\right]
\end{aligned}
$$

Where, $X$ is given data set, $M_{l}$ is candidate model, and $k_{l}$ is the number of freedom parameter.

Based on agile manufacturing resource excavating and predicating strategy, each manufacturing resource saves an agile manufacturing resource metadata. The manufacturing resources include more route information than tradition manufacturing resource scheduling methods. When a manufacturing resource need be planned, manufacturing resource will be fast selected by excavating and predicating route information.

Agile manufacturing resource excavating and predicating model based HMM.Based on the excavating and predicating route information of agile manufacturing resource, agile manufacturing resource excavating and predicating model is constructed by means of agile manufacturing resource excavating and predicating strategy to fast select and plan optimal manufacturing resource in agile manufacturing mode or other network manufacturing mode. The agile manufacturing resource excavating and predicating model is shown as Figure 3.

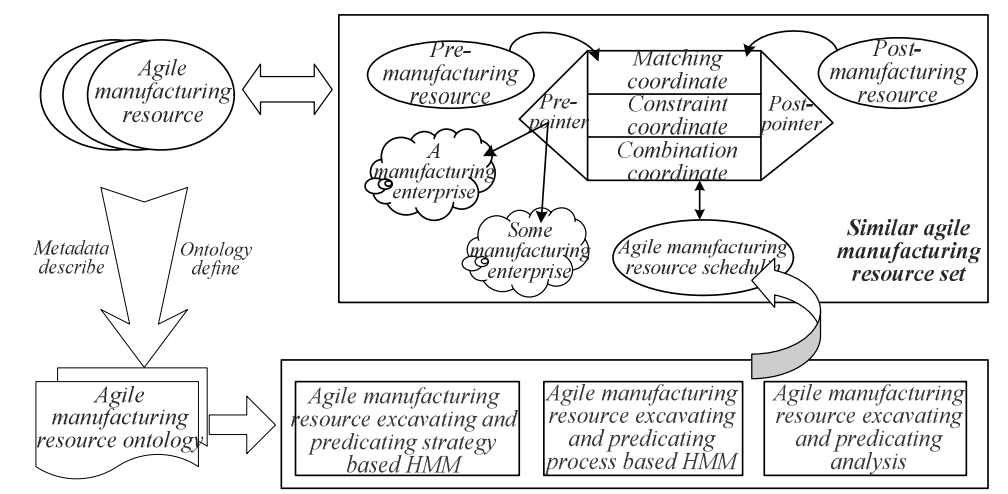

Fig.3. Agile manufacturing resource excavating and predicating model based HMM 
By means of agile manufacturing resource excavating and predicating model based HMM, the status information of clustering resources can be provided and beginning and ending services can be managed by agile manufacturing mode. It is direct relation between resources and users. The abstract function of task and safe conduct of operation task can be provided by agile manufacturing resource excavating and predicating strategy based HMM. The service of manufacturing resources can received the demand of resources scheduling, and can manage service data by means of status and condition of resources. Based on the least task priority and the minimum expected waiting time optimizing strategies, the excavating and predicating from task to manufacturing resources (includes task construction, task activation, task operation, task update, and so on). When a user applies a task, this task will be distributed into manufacturing resources task queue by agile manufacturing resource excavating and predicating model based HMM. This manufacturing resources task queue is to manage safe mapping of task, the identification of task, the smooth operation of task. The manufacturing resources excavating and predicating task can be directed to corresponding manufacturing resource. If the manufacturing resources non-existent, manufacturing resources excavating and predicating task can be directed to other manufacturing resources to assure the steady operation of manufacturing process in agile manufacturing mode. It can further meet manufacturing resource selection and scheduling demand in agile manufacturing mode resource management environment

\section{Conclusion}

In this paper, agile manufacturing resource ontology infrastructure was established by means of agile manufacturing resource modularization metadata and ontology. On this basis, agile manufacturing resource excavating and predicating strategy was constructed by the HMMof time series model. Finally, agile manufacturing resource excavating and predicating model was established to provide a supply for manufacturing resource selection and scheduling in agile manufacturing mode resource management environment, and to provide an approach for the knowledge extension of agile manufacturing resource excavating and predicating.

\section{References}

[1] Lin Zhang,Yongliang Luo, Fei Tao. Cloud manufacturing: a new manufacturing paradigm, Enterprise Information Systems. 8(2014) 167-187.

[2] Lihui Wang. Enterprise Networks and Logistics for Agile Manufacturing,Springer, 2010.

[3] M. L. R. Varela, G. D. Putnik, M. M. Cruz-Cunha, Web-Based Technologies Integration for Distributed Manufacturing Scheduling in a Virtual Enterprise, International Journal of Web Portals. 4(2012) 19-39.

[4]Davood Gharakhani, Amid Pourghafar Maghferati, Arshad Farahmandian, Rasol Nasiri. Agile manufacturing, Lean production, Just in Time systems and products quality improvemen, Life Science Journal.10(2013) 384-388.

[5]Mohammad D. AL-Tahat and Khaled M. Bataineh, Mathematical problems in engineering,statistical analyses and modeling of the implementation of agile manufacturing, Tactics in Industrial Firms. 2012 1-23.

[6] Linan Zhu,Yanwei Zhao, and WanliangWang. A Bilayer Resource Model for Cloud Manufacturing Services, Mathematical Problems in Engineering. 2013,1-23.

[7] Mahsa Naseri, Simone A. Ludwig, Evaluating workflow trust using hidden markov modeling and provenance data, data provenance and data management in e-service, Studies in Computational Intelligence, 426(2013) 35-58. 
[8] Oskar Kochana, Patrycja Ksiazek, Michal Olszak, Ewa Bielinska, Bilinear time series model as an alternative way of speaker modeling, Nostradamus 2014: Prediction, Modeling and Analysis of Complex Systems Advances in Intelligent Systems and Computing. 289(2014) 241-250. 